\title{
A note on the early transcriptional response in leaves and root of potato plants to cadmium exposure
}

\author{
M.F. Mengist ${ }^{1 *}$, S.L. Byrne ${ }^{1 \dagger}$, D. Griffin ${ }^{1}$, D. Milbourne ${ }^{1}$ \\ ${ }^{1}$ Teagasc, Crop Science Department, Oak Park, Carlow R93 XE12, Ireland \\ *Present address: Plants for Human Health Institute, North Carolina State University, NCRC, 600 Laureate Way, Kannapolis, NC 28081, USA
}

Abstract

Potato plants can accumulate a high amount of cadmium $(\mathrm{Cd})$ in the tuber when grown in soils rich in Cd. The molecular mechanisms governing Cd accumulation in the potato plant are poorly understood. Here we performed an RNA-sequencing experiment to identify genes differentially expressed in the leaf and root of potato during early stages of $\mathrm{Cd}$ exposure. Results did not identify any significant transcriptional response in leaves under 1 or $5 \mathrm{mg} \mathrm{kg}^{-1} \mathrm{Cd}$ after $72 \mathrm{~h}$. However, in the roots we did identify 2,846 genes that were significantly differentially expressed after $72 \mathrm{~h}$ between plants grown in $5 \mathrm{mg} \mathrm{kg}^{-1} \mathrm{Cd}$ and controls. These included genes involved in photosynthesis and autophagy being up-regulated, and genes involved in intracellular transport being downregulated. This study is the first report on the transcriptome-wide response of potato to Cd stress, providing insight into the molecular mechanisms involved in the response.

Keywords

Cadmium $\cdot$ gene expression $\cdot$ potato $\cdot$ RNA-seq $\cdot$ transcriptome

\section{Introduction}

Cadmium ( $\mathrm{Cd}$ ) is a toxic metal for animals and humans if consumed in sufficient quantities (Clemens, 2006; Grant et al., 2008; Mengist et al., 2017, 2018a, 2018b). Cadmium has similar physicochemical properties to $\mathrm{Zn}$, both being included in Group 12 of the periodic table. Cadmium is predominantly found in the earth's crust in association with zinc, lead and copper ores. Natural processes such as weathering and volcanic activities release $\mathrm{Cd}$ to the environment. However, these natural processes result in only trace levels of $\mathrm{Cd}$ being released (Clemens, 2006). The main sources of $\mathrm{Cd}$ in the environment are smelting, fossil fuel combustion, municipal waste incineration and disposal and agricultural practices including the application of sewage sludge and phosphate fertilisers, as Cd occurs naturally in rock phosphate (Clemens, 2006; Clemens et al., 2013; Roberts, 2014).

Cadmium is taken up by the basal roots, translocated to the shoot via the xylem and redistributed to the tuber via the phloem (Reid et al., 2003; Mengist et al., 2017). During the processes of "import and export", factors associated with uptake, transport and distribution can determine the final tuber Cd (Clemens, 2006; Clemens et al., 2013; Mengist et al.,
2017, 2018b). Our previous studies revealed differences in Cd uptake and distribution among potato cultivars. Root $\mathrm{Cd}$ absorption, root-to-shoot translocation and distribution of $\mathrm{Cd}$ between organs were the major limiting factors for differential Cd accumulation in tuber of potato (Mengist et al., 2017, 2018b). Furthermore, the role of shoots and roots for $\mathrm{Cd}$ uptake and distribution was examined at two Cd concentrations (1 $\mathrm{mg} \mathrm{kg}^{-1}$ and $5 \mathrm{mg} \mathrm{kg}^{-1}$ soil $\mathrm{Cd}$ ). The pattern of $\mathrm{Cd}$ concentrations was different among organs in the two Cd treatments; at the low soil $\mathrm{Cd}$ level ( $1 \mathrm{mg} \mathrm{kg}^{-1}$ soil $\mathrm{Cd}$ ) there were similar levels of $\mathrm{Cd}$ in shoots and roots. In contrast, the root sequestered much higher $\mathrm{Cd}$ than the shoot at higher $\mathrm{Cd}$ treatment $\left(5 \mathrm{mg} \mathrm{kg}^{-1}\right.$ soil $\mathrm{Cd}$ ). Regardless of the soil Cd levels, tuber Cd concentrations were much smaller than root or shoot $\mathrm{Cd}$ concentrations (Mengist et al., 2018b).

The molecular mechanisms by which plants respond to changes in Cd stress are complex but of great importance and could be useful in developing strategies for elucidating the gene networks involved in plant responses to various kinds of stress (Oono et al., 2016). Cadmium is non-essential to plant cells and it is believed that plants do not have Cd-specific membrane transporters. Instead, Cd uptake and transport 
can be associated with other cation transporters, such as $\mathrm{Zn}^{2+}$ and $\mathrm{Fe}^{2+}$ transporters, because of the similar chemical properties exhibited by these cations (Sanita di Toppi \& Gabbrielli, 1999; Clemens, 2006; Broadley et al., 2007; Sasaki et al., 2012; Brunetti et al., 2015). Elevated levels of Cd in the plant cells can be immobilised in the apoplasm (metal binding to the cell wall and intercellular spaces), chelation in the cytoplasm, compartmentalisation in the vacuole, loading to the xylem and translocation to the shoot and/or efflux back to the soil solution (Sanita di Toppi \& Gabbrielli, 1999; Clemens et al., 2001; Broadley et al., 2007). Furthermore, ATP-binding cassette $(A B C)$ transporters are involved in the transport of Cd complexes to the vacuoles (Song et al., 2010; Park et al., 2012; Brunetti et al., 2015).

Genome-wide profiling of the transcriptome is helpful to understand the functional elements of the genome, cells and tissues, and their roles in the development of resistance or tolerance to abiotic or biotic stresses (Wolf, 2013). RNA-seq analyses have been applied for Cd stress in different crops, including rice (Oono et al., 2016), tomato (Hou et al., 2017) and other Solanum species (Xu et al., 2012). However, to date, there has been no report regarding molecular mechanisms of $\mathrm{Cd}$ accumulation in potato. In this study, we aimed to identify differentially expressed genes and associated pathways under Cd stress using RNA-seq analysis from leaf and root organs of the potato cultivar, "Rooster", exposed to two different $\mathrm{Cd}$ concentrations ( $1 \mathrm{mg} \mathrm{kg}^{-1}$ and $5 \mathrm{mg} \mathrm{kg}^{-1}$ soil $\mathrm{Cd}$ ) conditions.

\section{Materials and methods}

\section{Experimental design and RNA extraction}

Virus-free tubers of the variety Rooster were sprouted under constant diffused light conditions and planted in $10 \mathrm{~L}$ pots filled with a sand-soil mixture under controlled greenhouse conditions with $16 \mathrm{~h}$ light at $21^{\circ} \mathrm{C}$. The plants were watered from above daily with $1 \mathrm{~L}$ nutrient solution as described in Dunbar et al. (2003). Briefly, the nutrient solution comprised (mM) $3.0 \mathrm{KNO}_{3}, 1.0 \mathrm{MgSO}_{4}, 0.5 \mathrm{NaCl}, 2.5 \mathrm{CaNO}_{3}, 0.5$ $\mathrm{K}_{2} \mathrm{SO}_{4}$ and $0.5 \mathrm{KH}_{2} \mathrm{PO}_{4}$. Micronutrients (in $\mu \mathrm{M}$ ) were 20 $\mathrm{B}, 20 \mathrm{Mn}, 10 \mathrm{Zn}, 1.0 \mathrm{Cu}$ and $0.5 \mathrm{Mo}$. Iron (25 mM) was added as a complex with diethylene triamine penta-acetic acid. The nutrient solution was adjusted to a $\mathrm{pH}$ of 5.5 with $\mathrm{HCl}$. During the growth period, the plants were rotated every day to have uniform light exposure. At $45 \mathrm{~d}$ of planting, the plants were randomly assigned to one of three treatments. Plants in the first treatment did not receive any $\mathrm{Cd}$ and acted as the experimental control, plants in the second treatment received $1 \mathrm{mg} \mathrm{kg}^{-1} \mathrm{Cd}$ for $72 \mathrm{~h}$ and plants in the third treatment received $5 \mathrm{mg} \mathrm{kg}^{-1} \mathrm{Cd}$ for $72 \mathrm{~h}$. Cd was applied in the form of $\mathrm{CdCl}_{2}$ with the nutrient solution. Youngest leaves from the third row of the canopy were collected and flash frozen in liquid nitrogen and stored at $-80^{\circ} \mathrm{C}$ until further processing. Similarly, the root samples were carefully washed with distilled water and kept at $-80^{\circ} \mathrm{C}$ until further processing.

Total RNA extraction from leaf and root tissue was performed using Trizol reagent (Invitrogen, Waltham, MA, USA). The RNA concentration and purity was analysed by NanoDrop 1000 Spectrophotometer (Thermo Fisher Scientific, Loughborough, UK). A260/A280 ratios were used to determine purity. RNA quality was also determined using the 2100 Bioanalyzer (Agilent Technologies, Santa Clara, CA, USA). The RNA Nano 6000 chip was used and RNA integrity numbers (RINs) were calculated using manufacturer's software. All samples had an RIN greater than 8 and were used in subsequent analysis.

\section{Library preparation and sequencing}

Twenty-four samples (two organs, three treatments, each with four biological replicates) were submitted to LC Sciences (Houston, TX, USA) for complementary DNA (cDNA) library preparation and RNA sequencing. Twenty-four cDNA libraries were constructed using the TruSeq RNA sample Prep Kit (Illumina, San Diego, CA, USA) following manufacturer's instructions. The libraries were sequenced with an Illumina HiSeq 2000 sequencer, aiming to generate stranded $150 \mathrm{bp}$ paired-end reads with a minimum of 30 million pairs per sample. The data have been deposited in European Bioinformatics Institute's ArrayExpress and has been assigned the accession number E-MTAB-7711.

\section{Transcript quantification and differential expression} RNA-seq data were pseudoaligned to the reference transcriptome (The Potato Genome Sequencing Consortium, 2011), and transcript abundance determined using Kallisto (Bray et al., 2016). Differential gene expression was carried out using Sleuth (Pimentel et al., 2017) with four pairwise comparisons performed (leaf and root samples at both 1 and $5 \mathrm{mg} \mathrm{kg}^{-1} \mathrm{Cd}$ for $72 \mathrm{~h}$, each compared to controls). To identify the transcripts affected by $\mathrm{Cd}$ we ran a likelihood ratio test (LRT). A Wald test was also run to determine $\beta$ estimates and only transcripts overlapping with the LRT analysis were retained. Gene ontology enrichment analysis was carried out using ShinyGO (Ge et al., 2020).

\section{Results}

\section{Plant growth and transcript quantification}

At the time of harvest, we did not see any symptoms of stress or differences between the treated and control samples. Root and leaf samples from both treated and control conditions 


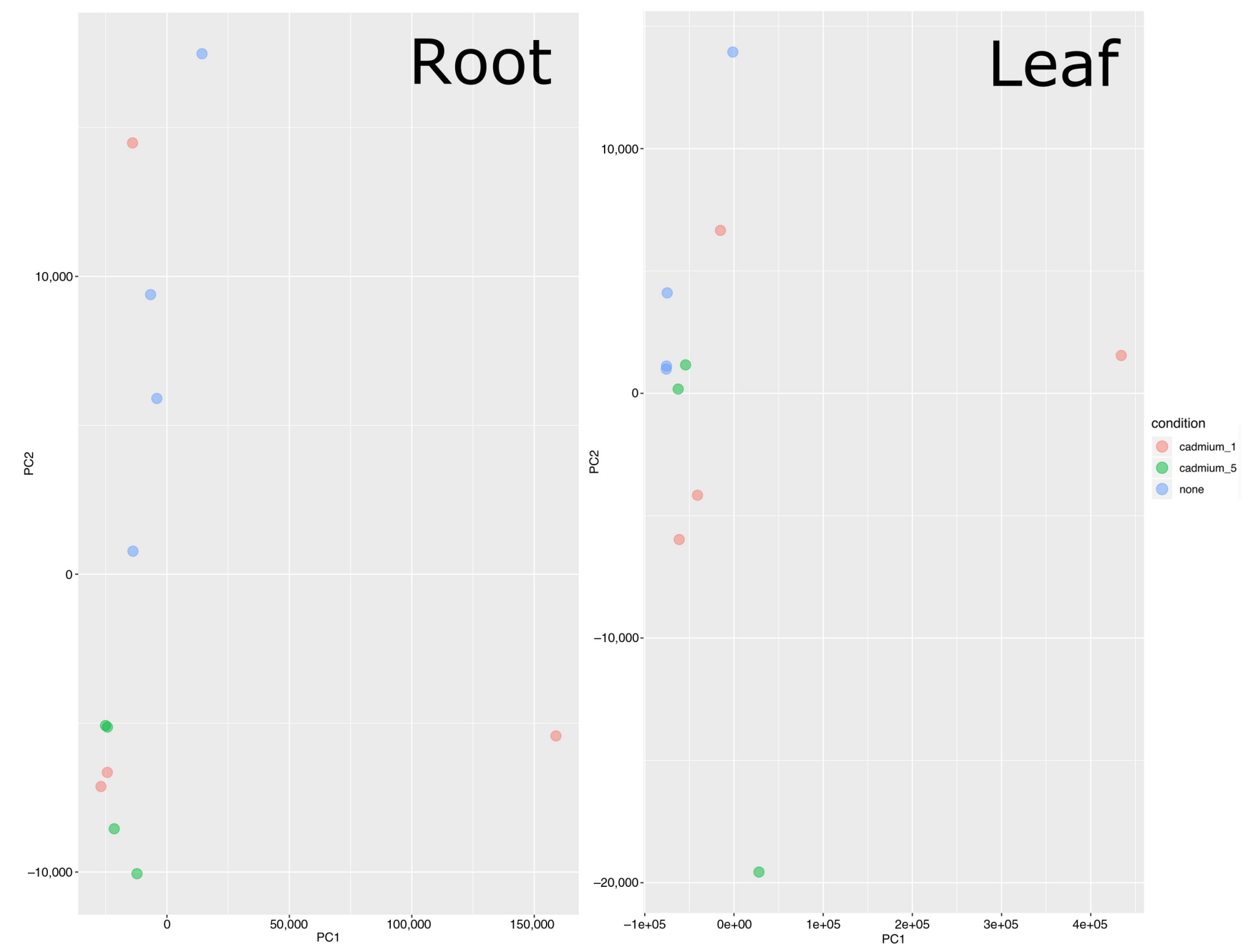

Figure 1. Principle component analysis of RNA-seq data. The first and second principle components of transcript abundance data in leaf and root of control, and 1 or $5 \mathrm{mg} \mathrm{kg}^{-1} \mathrm{Cd}$ after $72 \mathrm{~h}$. The outlier sample on PC1 in leaf is $1 \mathrm{mg} \mathrm{kg}^{-1} \mathrm{Cd}$, and the outlier sample on PC1 in root is $1 \mathrm{mg} \mathrm{kg}^{-1} \mathrm{Cd}$.

were collected and RNA extracted for library preparation and sequencing. A total of 23 strand-specific cDNA libraries (11 from leaves and 12 from roots) were constructed and sequenced on an Illumina HiSeq, generating paired-end reads ranging between 35.58 million pairs per sample and 70.87 million pairs per sample. A single leaf sample $\left(5 \mathrm{mg} \mathrm{kg}^{-1} \mathrm{Cd}\right)$ was removed from analysis due to a problem with the data file. Reads were aligned to the transcriptome with Kallisto and resulted in mapping rates between $71 \%$ and $78 \%$ with the exception of one leaf $\left(1 \mathrm{mg} \mathrm{kg}^{-1} \mathrm{Cd}\right)$ and one root (1 $\mathrm{mg} \mathrm{kg}^{-1} \mathrm{Cd}$ ) sample (59\% and 65\%). Principal component analysis (PCA) on leaf and root samples did not show clear separation among treatments in leaf samples; however, there was separation on PC2 between control and $5 \mathrm{mg} \mathrm{Cd}$ in root samples (Figure 1). The single root and leaf samples that appear as outliers on the PCA are the two samples with the lower mapping rates identified above. A case could be made for removing these samples but they have been retained for the analysis presented here.

\section{Differential gene expression under Cd treatment}

In leaf we did not find any genes significantly differentially up- or down-regulated with our analysis approach under either 1 or $5 \mathrm{mg} \mathrm{kg}^{-1} \mathrm{Cd}$ for $72 \mathrm{~h}$. In root we also did not find any genes significantly differentially up- or down-regulated under $1 \mathrm{mg} \mathrm{kg}^{-1} \mathrm{Cd}$ for $72 \mathrm{~h}$; however, we did identify differentially expressed genes in root under $5 \mathrm{mg} \mathrm{kg}^{-1} \mathrm{Cd}$ for $72 \mathrm{~h}$. In total we identified 2,846 genes differentially expressed between control and $5 \mathrm{mg} \mathrm{kg}^{-1} \mathrm{Cd}$ after $72 \mathrm{~h}$ (1,406 were down-regulated and 1,440 were up-regulated) 

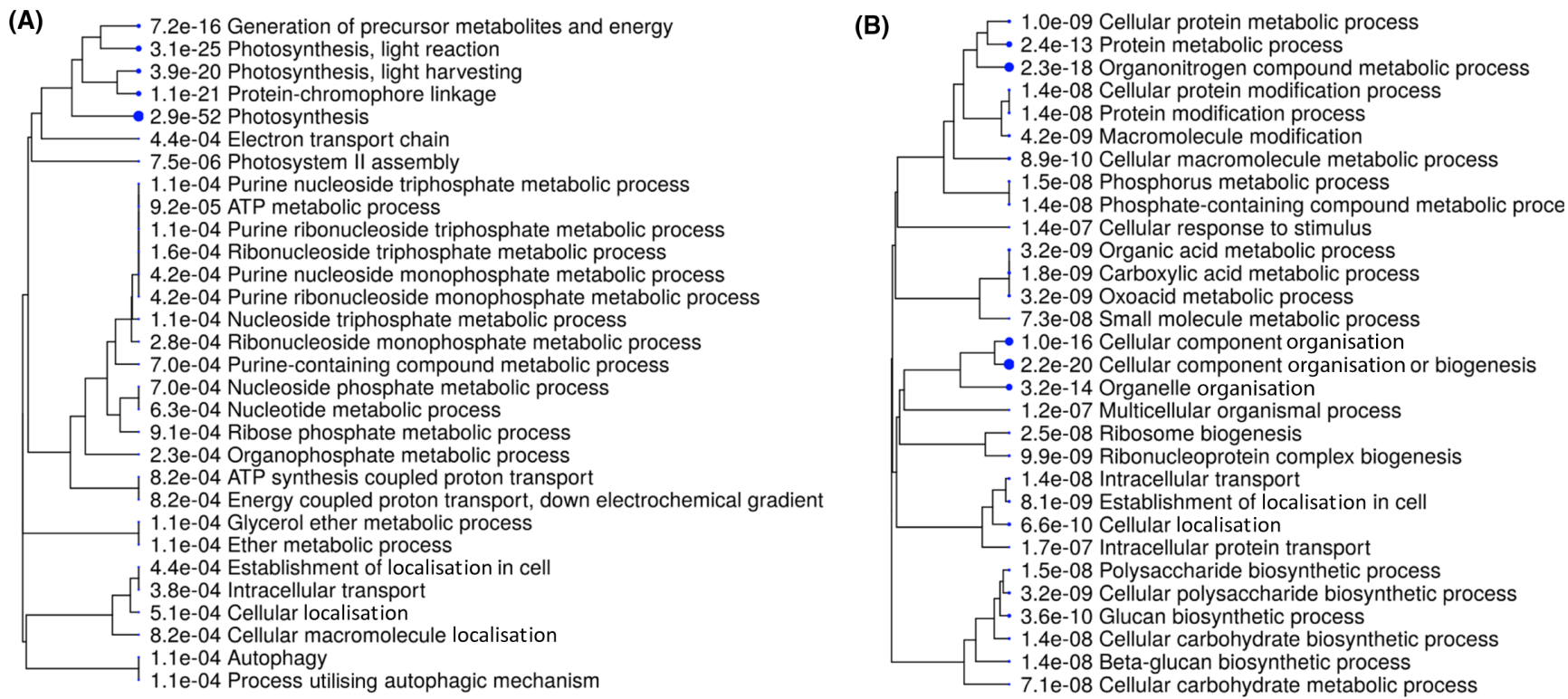

Figure 2. Gene ontology enrichment analysis. Hierarchical clustering of the top 30 significantly enriched categories in up-regulated (A) and down-regulated (B) lists of significantly differentially expressed transcripts in roots in response to $5 \mathrm{mg} \mathrm{kg}^{-1} \mathrm{Cd}_{\text {after }} 72 \mathrm{~h}$. The size of blue dots alongside functional category corresponds to level of significance.

(https://doi.org/10.6084/m9.figshare.11114576.v1). Gene ontology enrichment analysis identified functional categories significantly enriched in both up- and down-regulated gene lists (Figure 2). In the up-regulated gene list, there were 38 genes mapped to the GO term Response to chemical, including a heavy-metal-associated domain containing protein (PGSC0003DMT400001367), and a collection of auxin responsive family proteins (deposit on Figshare prior to publication [private link to data for review https:// figshare.com/s/e94cadf822173ad1a773]). Similarly, in the down-regulated gene list there were 53 genes mapped to the GO term Response to chemical, including peroxidase and glutathione reductase (https://doi.org/10.6084/ m9.figshare.11114576.v1).

\section{Discussion}

To date, there have been no published studies investigating the molecular mechanisms of $\mathrm{Cd}$ tolerance in potato. This study used untargeted transcriptome profiling to examine molecular and cellular processes affected by early $\mathrm{Cd}$ exposure in leaves and roots of potato. We failed to identify any response in the transcriptome of leaves under 1 or $5 \mathrm{mg} \mathrm{kg}^{-1}$ $\mathrm{Cd}$ after $72 \mathrm{~h}$. In line with these results, we did not identify any observable difference after $72 \mathrm{~h}$ between plants grown under $\mathrm{Cd}$ and controls. However, in the roots we did identify 2,846 genes that were significantly differentially expressed after $72 \mathrm{~h}$ between plants grown in $5 \mathrm{mg} \mathrm{kg}^{-1} \mathrm{Cd}$ and controls.

The functional category Photosynthesis was significantly enriched (72 genes assigned) in the up-regulated genes, which includes ultraviolet-B-repressible proteins, oxygenevolving enhancer protein, thioredoxin and photosystem II proteins among others. Previous research has identified that photosynthesis-related activities are modulated under $\mathrm{Cd}$ treatment (Tang et al., 2016; Chen et al., 2018), and it is already known that heavy metals such as $\mathrm{Cd}$ can damage chloroplasts and disrupt photosynthesis (Paunov et al., 2018). Furthermore, the use of the photosynthetic apparatus in the development of biosensors to monitor heavy metal contamination has been proposed (Rouillon et al., 2006). The functional category Autophagy was also significantly enriched (eight genes). Autophagy is a degradation and recycling pathway in plants, and it has been shown to be induced on exposure to heavy metals (Zheng et al., 2012). A study in tobacco seedlings recently demonstrated that 18 of 30 autophagy-related genes characterised were up-regulated in response to at least one heavy metal, including Cd (Zhou et al., 2015). Our results suggest that activation of autophagy also occurs in potato.

A Synaptotagmin gene (PGSC0003DMT400089685) showed the greatest down-regulation in roots under $\mathrm{Cd}$. An Arabidopsis synaptotagmin gene (SYTA) was shown to regulate endocytosis and virus movement protein cell-to-cell transport (Lewis \& Lazarowitz, 2010). Endocytosis provides 
a major route for membrane proteins, lipids and extracellular molecules into the cell and is required for multiple cellular processes including nutrient uptake (Fan et al., 2015). Interestingly, Cd has been shown to disrupt endocytosis during pollen germination and tube growth in the conifer Picea wilsonii (Wang et al., 2014). Furthermore, a broad set of genes involved in directed movement of substances within a cell were down-regulated as indicated by the significant enrichment of the functional category Intracellular transport (34 genes assigned).

In conclusion, this study provides an insight into the early transcriptional response of potato to $\mathrm{Cd}$. While no genes were significantly regulated in leaves, a large number were regulated in roots in the highest $\mathrm{Cd}$ exposure, with genes involved in photosynthesis and autophagy being up-regulated, and intracellular transport being down-regulated.

\section{Acknowledgements}

The research was funded by the Irish Department of Agriculture, Food and the Marine (Project ref. no. 11SF308).

\section{References}

Bray, N.L., Pimentel, H., Melsted, P. and Pachter, L. 2016. Nearoptimal probabilistic RNA-seq quantification. Nature Biotechnology 34: 525-527.

Broadley, M.R., White, P.J., Hammond, J.P., Zelko, I. and Lux, A. 2007. Zinc in plants. New Phytologist 173: 677-702.

Brunetti, P., Zanella, L., De Paolis, A., Di Litta, D., Cecchetti, V., Falasca, G., Barbieri, M., Altamura, M.M., Costantino, P. and Cardarelli, M. 2015. Cadmium-inducible expression of the ABC-type transporter AtABCC3 increases phytochelatin-mediated cadmium tolerance in Arabidopsis. Journal of Experimental Botany 66: 3815-3829.

Chen, Y.K., Zhi, J.K., Zhang, H., Li, J., Zhao, Q.H. and Xu, J.C. 2018. Transcriptome analysis of Phytolacca americana L. in response to cadmium stress (vol 12, pg 2017). PLoS One 13: e0199721.

Clemens, S. 2006. Toxic metal accumulation, responses to exposure and mechanisms of tolerance in plants. Biochimie 88: 1707-1719.

Clemens, S., Schroeder, J.I. and Degenkolb, T. 2001. Caenorhabditis elegans expresses a functional phytochelatin synthase. European Journal of Biochemistry 268: 3640-3643.

Clemens, S., Aarts, M.G.M., Thomine, S. and Verbruggen, N. 2013. Plant science: the key to preventing slow cadmium poisoning. Trends in Plant Science 18: 92-99.

Dunbar, K.R., McLaughlin, M.J. and Reid, R.J. 2003. The uptake and partitioning of cadmium in two cultivars of potato (Solanum tuberosum L.). Journal of Experimental Botany 54: 349-354.

Fan, L.S., Li, R.L., PAN, J.W., Ding, Z.J. and Lin, J.X. 2015. Endocytosis and its regulation in plants. Trends in Plant Science 20: 388-397.
Ge, S.X., Jung, D. and Yao, R., 2020. ShinyGO: a graphical geneset enrichment tool for animals and plants. Bioinformatics 36: 2628-2629.

Grant, C.A., Clarke, J.M., Duguid, S. and Chaney, R.L. 2008. Selection and breeding of plant cultivars to minimize cadmium accumulation. Science of the Total Environment 390: 301-310.

Hou, J., Liu, X.H., Cui, B.S., Bai, J.H. and Wang, X.K. 2017. Concentration-dependent alterations in gene expression induced by cadmium in Solanum lycopersicum. Environmental Science and Pollution Research 24: 10528-10536.

Lewis, J.D. and Lazarowitz, S.G. 2010. Arabidopsis synaptotagmin SYTA regulates endocytosis and virus movement protein cell-tocell transport. Proceedings of the National Academy of Sciences of the United States of America 107: 2491-2496.

Mengist, M.F., Milbourne, D., Griffin, D., Mclaughlin, M.J., Creedon, J., Jones, P.W. and Alves, S. 2017. Cadmium uptake and partitioning in potato (Solanum tuberosum L.) cultivars with different tuber-Cd concentration. Environmental Science and Pollution Research 24: 27384-27391.

Mengist, M.F., Alves, S., Griffin, D., Creedon, J., Mclaughlin, M.J., Jones, P.W. and Milbourne, D. 2018a. Genetic mapping of quantitative trait loci for tuber-cadmium and zinc concentration in potato reveals associations with maturity and both overlapping and independent components of genetic control. Theoretical and Applied Genetics 131: 929-945.

Mengist, M.F., Milbourne, D., Alves, S., Mclaughlin, M.J., Jones, P.W. and Griffin, D. 2018b. Roles of shoots and roots in cadmium uptake and distribution in tubers of potato (Solanum tuberosum L). Plant and Soil 430: 139-149.

Oono, Y., Yazawa, T., Kanamori, H., Sasaki, H., Mori, S., Handa, H. and Matsumoto, T. 2016. Genome-wide transcriptome analysis of cadmium stress in rice. Biomed Research International 2016: Article ID 9739505, 9 pages.

Park, J., Song, W.Y., Ko, D., Eom, Y., Hansen, T.H., Schiller, M., Lee, T.G., Martinoia, E. and Lee, Y. 2012. The phytochelatin transporters AtABCC1 and AtABCC2 mediate tolerance to cadmium and mercury. Plant Journal 69: 278-288.

Paunov, M., Koleva, L., Vassilev, A., Vangronsveld, J. and Goltsev, V. 2018. Effects of different metals on photosynthesis: cadmium and zinc affect chlorophyll fluorescence in durum Wheat. International Journal of Molecular Sciences 19: 787.

Pimentel, H., Bray, N.L., Puente, S., Melsted, P. and Pachter, L. 2017. Differential analysis of RNA-seq incorporating quantification uncertainty. Nature Methods 14: 687-690.

Reid, R.J., Dunbar, K.R. and Mclaughlin, M.J. 2003. Cadmium loading into potato tubers: the roles of the periderm, xylem and phloem. Plant Cell and Environment 26: 201-206.

Roberts, T.L. 2014. Cadmium and Phosphorous Fertilizers: The Issues and the Science. Symphos 2013 - 2nd International Symposium on Innovation and Technology in the Phosphate Industry 83: 52-59.

Rouillon, R., Piletsky, S.A., Breton, F., Piletska, E.V. and Carpentier, R. 2006. Photosystem II Biosensors for Heavy Metals Monitoring. 
Biotechnological Applications of Photosynthetic Proteins: Biochips, Biosensors and Biodevices. Boston, MA: Springer US.

Sanita di Toppi, L. and Gabbrielli, R. 1999. Response to cadmium in higher plants. Environmental and Experimental Botany 41: 105-130.

Sasaki, A., Yamaji, N., Yokosho, K. and Ma, J.F. 2012. Nramp5 is a major transporter responsible for manganese and cadmium uptake in rice. Plant Cell 24: 2155-2167.

Song, W.Y., Park, J., Mendoza-Cozatl, D.G., Suter-Grotemeyer, M., Shim, D., Hortensteiner, S., Geisler, M., Weder, B., Rea, P.A., Rentsch, D., Schroeder, J.I., Lee, Y. and Martinoia, E. 2010. Arsenic tolerance in Arabidopsis is mediated by two ABCCtype phytochelatin transporters. Proceedings of the National Academy of Sciences of the United States of America 107: 21187-21192.

Tang, L., Yao, A.J., Yuan, M., Tang, Y.T., Liu, J., Liu, X. and Qiu, R.L. 2016. Transcriptional up-regulation of genes involved in photosynthesis of the $\mathrm{Zn} / \mathrm{Cd}$ hyperaccumulator Sedum alfredii in response to zinc and cadmium. Chemosphere 164: 190-200.

The Potato Genome Sequencing Consortium. 2011. The Potato Genome Consortium (Participants are listed alphabetically by institution.)., BGI-Shenzhen. et al. Genome sequence and analysis of the tuber crop potato. Nature 475: 189-195.

Wang, X., Gao, Y., Feng, Y., Li, X., Wei, Q. and Sheng, X. 2014. Cadmium stress disrupts the endomembrane organelles and endocytosis during Picea wilsonii Pollen Germination and Tube Growth. PLoS One 9: e94721.

Wolf, J.B.W. 2013. Principles of transcriptome analysis and gene expression quantification: an RNA-seq tutorial. Molecular Ecology Resources 13: 559-572.

Xu, J., Sun, J.H., Du, L.G. and Liu, X.J. 2012. Comparative transcriptome analysis of cadmium responses in Solanum nigrum and Solanum torvum. New Phytologist 196: 110-124.

Zheng, L.J., Peer, T., Seybold, V. and Lutz-Meindl, U. 2012. Pb-induced ultrastructural alterations and subcellular localization of $\mathrm{Pb}$ in two species of Lespedeza by TEM-coupled electron energy loss spectroscopy. Environmental and Experimental Botany 77: 196-206.

Zhou, X.M., Zhao, P., Wang, W., Zou, J., Cheng, T.H., Peng, X.B. and Sun, M.X. 2015. A comprehensive, genome-wide analysis of autophagy-related genes identified in tobacco suggests a central role of autophagy in plant response to various environmental cues. DNA Research 22: 245-257. 